\title{
Chronic measurement of left ventricular pressure in freely moving rats
}

\author{
Ellyce Stehlin, ${ }^{1}$ Simon C. Malpas, ${ }^{1,2,3}$ David M. Budgett, ${ }^{1,3}$ Carolyn J. Barrett, ${ }^{2}$ Daniel McCormick, ${ }^{1,3}$ \\ Gillian Whalley, ${ }^{4}$ Fumin Fu, ${ }^{5}$ Michael Beil, ${ }^{5}$ Dean F. Rigel, ${ }^{5}$ and Sarah-Jane Guild ${ }^{2,3}$ \\ ${ }^{1}$ Auckland Bioengineering Institute, University of Auckland, Auckland, New Zealand; ${ }^{2}$ Department of Physiology, University of \\ Auckland, Auckland, New Zealand, ${ }^{3}$ Millar Inc, Auckland, New Zealand; ${ }^{4}$ Faculty of Social and Health Sciences, Unitec, Auckland, \\ New Zealand; and ${ }^{5}$ Novartis Institutes for BioMedical Research, Novartis Pharmaceuticals Corporation, East Hanover, New Jersey
}

Submitted 13 June 2013; accepted in final form 8 October 2013

\begin{abstract}
Stehlin E, Malpas SC, Budgett DM, Barrett CJ, McCormick D, Whalley G, Fu F, Beil M, Rigel DF, Guild S-J. Chronic measurement of left ventricular pressure in freely moving rats. $J$ Appl Physiol 115: 1672-1682, 2013. First published October 10, 2013; doi:10.1152/japplphysiol.00683.2013.-Measurements of left ventricular pressure (LVP) in conscious freely moving animals are uncommon, yet could offer considerable opportunity for understanding cardiovascular disease progression and treatment. The aim of this study was to develop surgical methods and validate the measurements of a new high-fidelity, solid-state pressure-sensor telemetry device for chronically measuring LVP and $\mathrm{dP} / \mathrm{d} t$ in rats. The pressure-sensor catheter tip (2-Fr) was inserted into the left ventricular chamber through the apex of the heart, and the telemeter body was implanted in the abdomen. Data were measured up to 85 days after implant. The average daytime $\mathrm{dP} / \mathrm{d} t$ max was $9,444 \pm 363 \mathrm{mmHg} / \mathrm{s}$, ranging from 7,870 to $10,558 \mathrm{mmHg} / \mathrm{s}(n=7)$. A circadian variation in $\mathrm{dP} / \mathrm{d} t$ max and heart rate (HR) was observed with an average increase during the night phase in $\mathrm{dP} / \mathrm{d} t$ max of $918 \pm 84 \mathrm{mmHg} / \mathrm{s}$, and in HR of $38 \pm$ $3 \mathrm{bpm}$. The $\beta$-adrenergic-agonist isoproterenol, $\beta_{1}$-adrenergic agonist dobutamine, $\mathrm{Ca}^{2+}$ channel blocker verapamil, and the calcium sensitizer levosimendan were administered throughout the implant period, inducing dose-dependent time course changes and absolute changes in $\mathrm{dP} / \mathrm{d} t$ max of $-6,000$ to $+13,000 \mathrm{mmHg} / \mathrm{s}$. The surgical methods and new technologies demonstrated long-term stability, sensitivity to circadian variation, and the ability to measure large drug-induced changes, validating this new solution for chronic measurement of LVP in conscious rats.
\end{abstract}

telemetry; solid-state pressure; inductive power; $\mathrm{dP} / \mathrm{d} t$

STABLE, ACCURATE MEASUREMENTS of left ventricular pressure (LVP) can provide key indicators of cardiac performance for basic cardiovascular performance through to the safety assessment of therapeutic compounds. Traditionally, it has been possible to obtain an index of contractility via the placement of a pressure sensor into the left ventricular chamber and calculating the first derivative of ventricular pressure, the change in pressure over time $(\mathrm{dP} / \mathrm{d} t)(11)$. Such measurement is commonplace in anesthetized rodents but has received little attention in the conscious condition. Although measurement of arterial blood pressure in freely moving rodents via telemetry is widely practiced (10), there have been very few recordings of LVP and $\mathrm{dP} / \mathrm{d} t$ in the conscious state $(1,20,23)$. A direct chronic measure of LVP and its first derivative, $(\mathrm{LV} \mathrm{dP} / \mathrm{d} t)$, poses a greater surgical challenge compared with arterial pressure measurements. This is because it has been generally considered that placement of the pressure catheter via the carotid and through the aortic valve is not chronically viable due to the risk of valve

Address for reprint requests and other correspondence: S.-J. Guild, Dept. of Physiology, Univ. of Auckland, Private Bag 92019, Auckland, New Zealand (e-mail: s.guild@auckland.ac.nz). damage (17). This necessitates a more complicated surgical approach through the wall of the left ventricle (LV). Although surgical approaches have been described $(1,23)$, there has been little assessment of their long-term validity. Importantly, the pressure dynamics occurring in the LV have a greater rate of change compared with arterial pressure, requiring a sensor with a high-frequency response for accurate signal capture. Arterial pressure telemeters have traditionally relied on a gel-filled catheter-based pressure-sensing mechanism with a relatively limited frequency response $(10,13,23,25)$. Control $\mathrm{LV} \mathrm{dP} / \mathrm{d} t$ max values reported for the rat using this technology have varied widely, from 5,000 to $13,000 \mathrm{mmHg} / \mathrm{s}(3,4)$, suggesting a possible error associated with the lower frequency response. Overall, whereas some day/night variation in $\mathrm{dP} / \mathrm{dt}$ max has been reported, the values obtained appear to be confounded by the limitation of the technology (23). Solid-state pressure sensors provide an opportunity for high-fidelity recordings of pulsatile pressures such as those occurring in the LV but have not been applied to the chronic measurement of LVP. The aim of this study was to refine and evaluate surgical approaches to implanting LV catheters for the chronic measurement of LVP. The potential of a new, solid-state telemetry system for accurately measuring LVP was investigated under a range of conditions in freely moving rats. In particular, the ability of the device to accurately measure changes in $\mathrm{dP} / \mathrm{d} t$ was assessed through measurement of the long-term circadian variation and direct drug-induced alteration of LVP.

\section{MATERIALS AND METHODS}

\section{Modeled Error in Determining $d P / d t$}

Because previous telemetry-based recordings of LVP have utilized fluid-filled catheters, we believed it was important to estimate the ability of a variety of telemetry technologies to accurately measure $\mathrm{dP} / \mathrm{d} t$. The frequency response of a variety of commercially available telemetry systems from Data Sciences International has been published $(5,13)$. We measured frequency response of a new solid-state telemeter (model TRM54P; Millar, Auckland, New Zealand) by a previously described method (13) in which an $18 \mathrm{mmHg}$ peak-to-peak sinusoidal pressure signal was applied to the sensor with discrete increases in frequency between 1 and $10 \mathrm{kHz}$. The $-3 \mathrm{~dB}$ frequency from the constructed Bode plot of the new sensor's output response was found to be $470 \mathrm{~Hz}$ (Fig. 1A). By taking the frequency response data from the Data Sciences $\mathrm{C} 40(3 \mathrm{~dB}$ point $40 \mathrm{~Hz}), \mathrm{C} 10(3 \mathrm{~dB}$ point $57 \mathrm{~Hz}), \mathrm{HD}-\mathrm{S} 21(3 \mathrm{~dB}$ point $100 \mathrm{~Hz})$, and TRM54P solid-state telemetry $(3 \mathrm{~dB}$ point $470 \mathrm{~Hz})$ systems we made a theoretical assessment of the ability of the different systems to measure a rate of change in pressure in the range that would be observed in the LV of a rat. MATLAB was used to generate fourth-order Bessel filters with a frequency response corresponding to 1.5 times the $-3 \mathrm{~dB}$ frequency for each sensor. A discrete series of ramp functions were simulated, each representing an increasing transient peak in $\mathrm{dP} / \mathrm{d} t(\mathrm{dP} / \mathrm{d} t \max )$ 

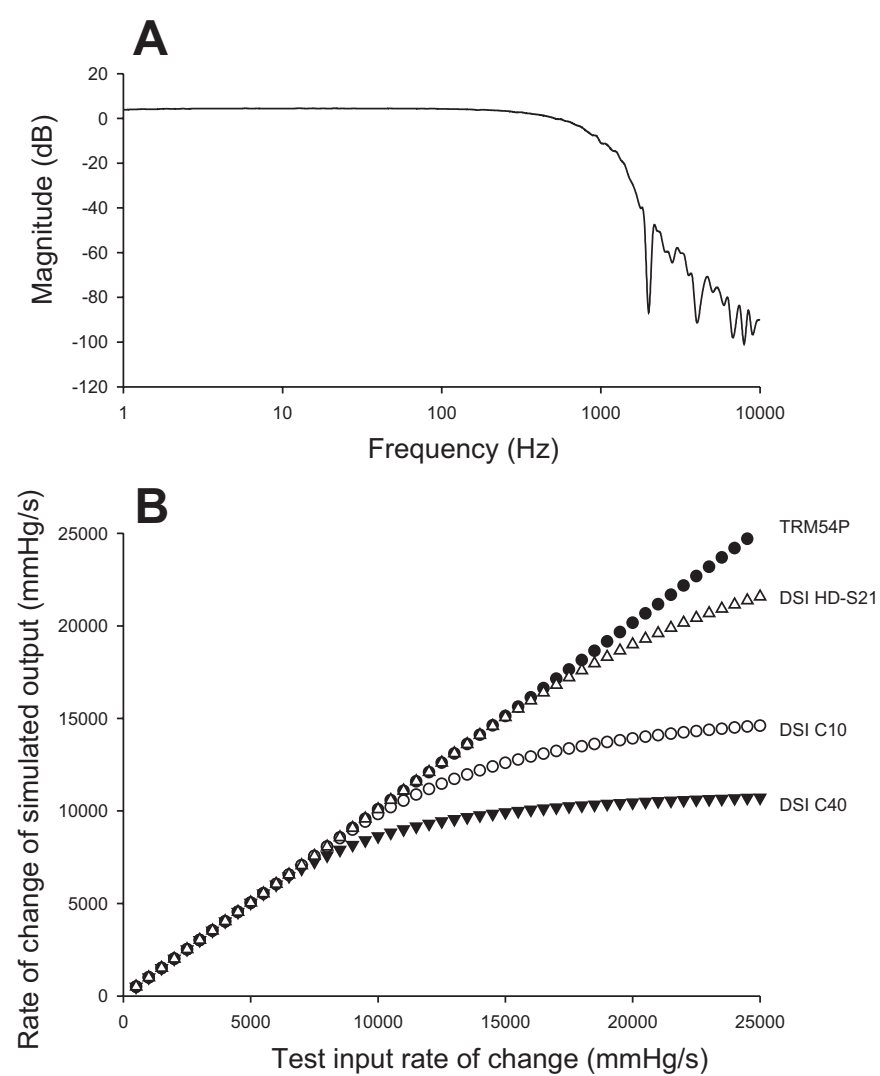

Fig. 1. A: average frequency response of the solid-state telemeter TRM54P showing a $-3 \mathrm{~dB}$ frequency of $470 \mathrm{~Hz}$. $B$ : frequency response-associated error for four telemetry devices. TRM54P ( $\bullet$ has a solid-state pressure sensing element on the end of a catheter, whereas DSI HD-S21 ( $\triangle$ ), DSI C10 (O), and DSI C40 ( $\mathbf{v})$ rely on a fluid catheter pressure-sensing mechanism. For a basal $\mathrm{dP} / \mathrm{d} t$ signal of $10,000 \mathrm{mmHg} / \mathrm{s}$, the simulation estimates TRM54P and DSI HD-S21 would measure $10,083 \mathrm{mmHg} / \mathrm{s}(<1 \%$ error), DSI $\mathrm{C} 10$ would measure $9,829 \mathrm{mmHg} / \mathrm{s}$ (1.7\% error), and DSI C40 would measure 8,633 $\mathrm{mmHg} / \mathrm{s}$ (14\% error). For a $\mathrm{dP} / \mathrm{d} t$ signal of $23,000 \mathrm{mmHg} / \mathrm{s}$ (as observed with dobutamine) the simulation estimates that TRM54P would measure 23,192 $\mathrm{mmHg} / \mathrm{s}(<1 \%$ error), DSI HD-S21 would measure $20,678 \mathrm{mmHg} / \mathrm{s}(10 \%$ error), DSI C10 would measure $14,380 \mathrm{mmHg} / \mathrm{s}$ (37\% error), and DSI C40 would measure 10,638 (54\% error). Note literature reports $\mathrm{dP} / \mathrm{d} t$ values obtained from anesthetized rats are between 5,000 and 13,000 $(3,4)$.

and passed through each filter representing the three sensors. The $\mathrm{dP} / \mathrm{d} t$ max of the resulting output was compared against the original function to determine the error in the signal due to the frequency response.

\section{Long-Term Drift}

A long-term drift apparatus was set up to monitor the drift in the pressure sensors and amplifier circuit used in the solid-state telemeters. The rig contained eight pressure sensor catheters immersed in saline housed in individual test tubes. The test tubes were housed in the dark in a heating block controlled at $37^{\circ} \mathrm{C}\left( \pm 0.2{ }^{\circ} \mathrm{C}\right)$. The catheters exited each test tube through a Touhy-Borst adapter with a separate opening to atmosphere through a hydrophobic filter to prevent evaporation. A benchtop digital pressure sensor (model CPT6100; Mensor, TX) with a zero stability of $0.11 \mathrm{mmHg}$ over 180 days (14) was used to monitor and compensate for atmospheric pressure changes. Pressure readings were taken from each sensor every 10 min for 100 days using a portable data logger (midi logger GL220; Graphtech, CA).
Animals

This study involved three groups of animals. Study of the first and second groups (Groups $A$ and $B$ ) were approved by the University of Auckland Ethics Committee. These groups contained male Wistar rats with initial weights of 300-320 g $(n=14$, Group A) and 281-385 g $(n=12$, Group B). Animals from Group A underwent varied surgery approaches to refine the surgical methods (see Surgery) and also received drugs to induce changes in LVP to test the technology's ability to measure change. Cardiac ultrasonography (Sonosite MicroMaxx with a 12-MHz sector transducer) was performed on a subset of Group A animals to determine fractional shortening (from m-mode) and fractional area change (from short axis images) of the heart pretelemeter implantation with the animal lightly anesthetized with isoflurane. Subsequently, animals in Group B all underwent the same established surgical method and received no interventions to produce chronic measurement data. Study of the third group of animals (Group $C$ ) was approved by the Novartis Animal Care and Use Committee. This separate group contained 9 male Wistar-Kyoto rats with initial weights between 545 and $715 \mathrm{~g}$. Animals in Group $C$ received varying doses of a range of compounds to induce dose-dependent time-course changes in LVP and $\mathrm{dP} / \mathrm{d} t$. All animals were housed individually with food and water constantly available. Individual fluid and food intake was monitored daily. The room was kept at a constant temperature $\left(22^{\circ} \mathrm{C}\right)$ and a $12: 12$-h dark:light cycle (lights-on from 6:00 A.M. to 6:00 P.M.).

\section{Surgery}

All animals were implanted with a TRM54P telemeter (Millar, Auckland, New Zealand) to measure LVP or a dual-channel device to measure LVP and electrocardiographic (ECG) recordings (TRM54PB) or LVP and blood pressure (BP) (TRM54PP). All devices shared the -3 $\mathrm{dB}$ point of $470 \mathrm{~Hz}$ of the TRM54P because they used the same pressure sensor. The sensing tip of the catheter utilized a 2-Fr solid-state pressure sensor (Millar, Houston, TX). Animals were initially anesthetized by inhalation of $4 \%$ isoflurane in $2-1 / \mathrm{min} \mathrm{O}_{2}$, followed by intubation, mechanical ventilation, and maintenance with $2 \%$ isoflurane. Antibiotic (Groups A and B: Baytril, enrofloxacin; Bayer, Auckland, New Zealand; Group C: Penject, penicillin G procaine; Butler Animal Health Supply, US) and analgesia (Temgesic, buprenorphine; Reckitt Benckiser, US) were given subcutaneously before the beginning of surgery.

\section{LVP Sensor Implantation}

Groups $A$ and $B$. A transdiaphragmatic approach was adopted with the pressure sensor placed in the LV and the telemeter body implanted in the abdomen. A $2.5-\mathrm{cm}$ abdominal midline incision was made in the skin starting from the xyphoid process and between the underlying abdominal muscles. A piece of saline-soaked gauze was used to protect exposed organs in the abdomen. A suture though the xyphoid process was used for gentle retraction to give a better view of the diaphragm and an incision was made in the diaphragm exposing the apex of the heart. A shallow suture was inserted in the apex of the heart so that it could be gently retracted to stabilize the heart. A 23-G needle was used to form a hole in the apex of the heart through which the pressure sensor was inserted into the LV. At this point the telemeter was turned on and the signal observed on a nearby computer while maneuvering the catheter tip to ensure the pressure sensing element of the catheter was inside the ventricular chamber and measuring a typical LVP waveform.

We assessed a variety of techniques to secure the sensor/catheter in the LV of Group A animals including tissue adhesive (Histoacryl, enbucrilate; B. Braun Melsungen, Germany), mesh patch, suture cuff, and a purse-string suture around the catheter. We found that the tissue adhesive, either used alone or in combination with a mesh patch, would hold the catheter in place for a few days but signal reliability would decrease with time and, in one animal, the catheter pulled out of the heart completely. The purse-string technique involved a series 
of shallow stitches made in the myocardium surrounding the catheter and gently pulled to restrict the catheter's movement. However, on its own, this was found not to be sufficient to secure the catheter in place. With the suture cuff technique, suture thread was wound around the catheter several times, tied and glued prior to beginning surgery to form a ring/cuff, $10 \mathrm{~mm}$ from the catheter's tip. Ten millimeters was measured as the distance from the apical epicardium to the catheter's tip, which would place the sensing element toward the base of the LV (i.e., the wider region). The thread then provided a stopper-to-catheter movement into the heart. A combination of suture cuff and pursestring was found to be the most reliable (Fig. 2), and this method was consistently used for the surgery of all Group $B$ animals.

The diaphragm was then sutured closed using individual stitches around the catheter, the final suture was prepared and pulled tight after the lungs were inflated by temporarily blocking the exhaust of the ventilator, and further air was suctioned out of the chest cavity by a syringe inserted through the remaining hole. The telemeter body was secured in the abdomen using a mesh pouch to anchor the telemeter to the abdominal muscle wall. The incision in the muscle layer was then sutured closed and staples were used to close the skin incision. A video of the full surgical method can be viewed online http://millar. $\mathrm{com} / / \mathrm{knowledge-center}$. After surgery the animals were left to recover initially overnight in a heated recovery box before being placed in their cage and starting recordings. Postsurgery treatment with analgesia (buprenorphine) continued for up to 2 days.

In several animals, a dual-channel telemeter was implanted with the same process for LVP surgery as described above in combination with either an ECG lead placement (TRM54PB; Millar) or a blood pressure catheter inserted into the abdominal aorta (TRM54PP; Millar). One ECG lead was placed on the xyphoid process and the second along the trachea in the mediastinum region (5).

Group $C$. The surgical technique for the Group $C$ rats was similar except that the catheter was inserted $\sim 9 \mathrm{~mm}$ from epicardium to tip, and a different anchoring method was used. In this case, a short length $(\sim 2 \mathrm{~mm})$ of Tygon tubing $(0.020$-in. ID $\times 0.060$-in. OD) was split

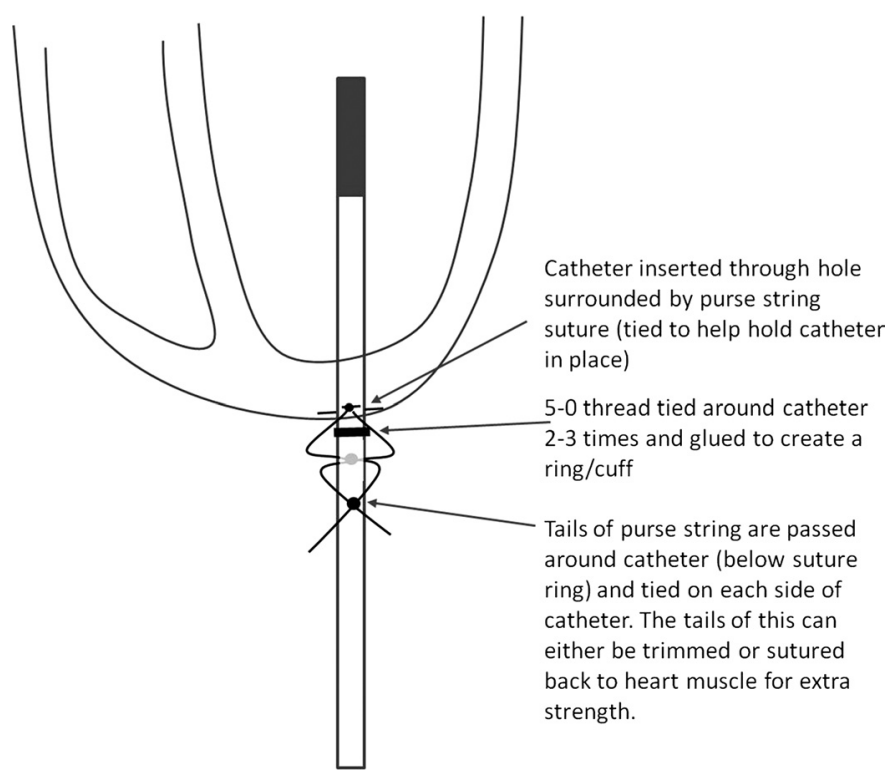

Fig. 2. Diagram of the most successful techniques used to secure the 2-Fr pressure-sensing catheter in the left ventricle. A circle of shallow stitches was made to form a purse-string at the apex of the heart and the catheter was inserted through the middle of the circle. In Group A rats, a presurgery glued-cuff of suture $10 \mathrm{~mm}$ from the tip of the catheter provided a guideline for how far to insert the catheter and a point to anchor the tails of the purse-string suture around the catheter. In Group B rats, a short section of longitudinally split tubing was slipped over and tied securely to the catheter with sutures, which were then tied to the tails of the purse-string sutures. longitudinally and placed around the catheter at the desired distance from the tip and secured to the catheter by a tightly tied suture. The catheter was inserted into the LV chamber up to the stopper tubing and secured by tying the ends of the tubing suture to the purse-string sutures. At least $2 \mathrm{wk}$ after the surgery to implant the LVP catheter, the rats underwent a second short surgery to implant a catheter in the femoral vein for drug delivery as described previously (21). Under isoflurane anesthesia (2-4\%), a femoral vein was isolated and catheterized. Catheters consisted of $55 \mathrm{~cm}$ of polyvinylchloride (Tygon) microbore tubing (0.020-in. ID, 0.060-in. OD) bonded with cyclohexanone to $4.5 \mathrm{~cm}$ of polyvinylchloride (0.011-in. ID, 0.024-in. OD; Biocorp Australia, Huntingdale, VIC, Australia) or Micro-Renathane (type MRE-025 polyurethane, 0.012-in. ID, 0.025-in. OD; Braintree Scientific, Braintree, MA) tubing. The catheters were tunneled subcutaneously and exteriorized in the mid-dorsal thoracic/abdominal region. The rats were allowed to recover for a minimum of $1 \mathrm{wk}$ before further interventions were performed. Catheters were flushed with sterile $0.9 \%$ saline and locked with $200 \mathrm{U} / \mathrm{ml}$ heparin in sterile $0.9 \%$ saline after the surgery was completed and at least twice per week thereafter.

\section{Technology and Data Acquisition}

The battery of the implanted telemeter was charged by an inductive pad (2) placed under the home cage of the rat. This pad (TR180 SmartPad; Millar, Auckland, New Zealand) also acted as a receiver for the LVP signals.

Groups $A$ and $B$. The received signals were sampled at $1 \mathrm{kHz}$ using a PowerLab and LabChart software (v7.3.5; ADInstruments, Sydney, Australia). In Group A, data were collected for 5 min every hour for up to 28 days, whereupon animals were euthanized with an overdose of sodium pentobarbital (150 mg ip), the telemeters were explanted, cleaned in an enzymatic detergent, and prepared and sterilized for reimplantation. Continuous data collection was implemented during drug interventions on Group A animals. Scheduled acquisition has previously been shown to accurately reflect the mean levels of arterial pressure and other cardiovascular variables (7). However, we found that in some Group A rats, spikes in the LVP data (as explained in RESULTS, Signal Quality) would coincide with the 5-min periods, particularly at night, resulting in significant loss of valuable data. Therefore, for Group B, data were recorded continuously throughout the implantation period. Twenty-eight to 40 days after implantation, Group B animals were again anesthetized using isoflurane and a 2-Fr acute Millar catheter was inserted into the LV via the right carotid artery (SPR-671; Millar Instruments). Several minutes of simultaneous LVP recording were made under anesthesia from both the telemeter and the acute catheter before the rats were euthanized with an overdose of pentobarbitone (150 mg i.p.). At postmortem of the rats in Group B, the heart tissue was carefully dissected away to allow visualization of the telemeter pressure sensor tip.

Group C. Data collection was performed using a Ponemah data acquisition system and software (Data Sciences International) and depended on the drug study protocol (see below for details). Implantation periods ranged from 24 to 85 days, when animals were euthanized by overdose with a saturating concentration of isoflurane. Both software packages used recorded the LVP signal and derived its first derivative with time $(\mathrm{dP} / \mathrm{d} t)$, maximal $\mathrm{dP} / \mathrm{d} t(\mathrm{dP} / \mathrm{d} t$ max $)$, minimum $\mathrm{dP} / \mathrm{d} t(\mathrm{dP} / \mathrm{dt} \mathrm{min})$, heart rate $(\mathrm{HR})$, and end systolic and end-diastolic pressure (EDP) per heartbeat.

\section{Drug-Induced Changes in LVP}

Group A. To assess the sensitivity of the technology to measure changes in $\mathrm{dP} / \mathrm{d} t$, the $\mathrm{Ca}^{2+}$ channel blocker verapamil $(10 \mathrm{mg} / \mathrm{kg} \mathrm{sc})$ or the $\beta$-adrenergic-agonist isoproterenol $(10 \mu \mathrm{g} / \mathrm{kg} \mathrm{sc})$ were administered a minimum of $2 \mathrm{wk}$ after the implantation surgery. Each drug and dose was selected to induce short-term (less than $2 \mathrm{~h}$ ) changes in heart function. Continuous recordings of beat-by-beat data were made 


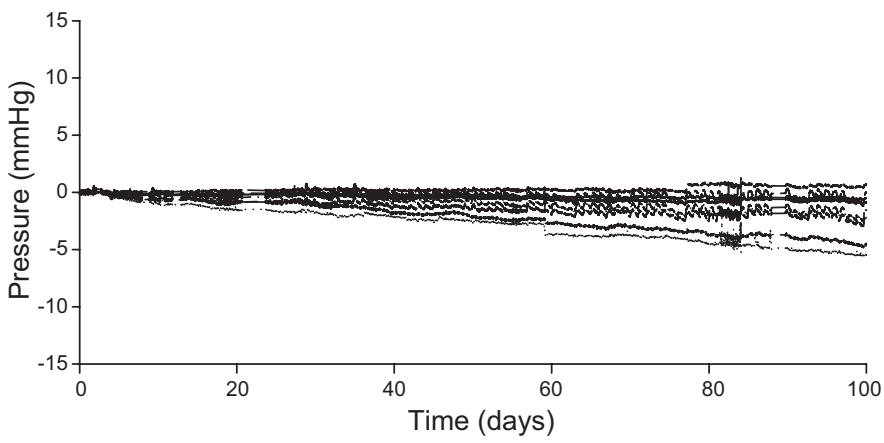

Fig. 3. Drift recorded in eight pressure sensors over 100 days. Pressure readings were taken every 10 min with atmospheric pressure compensation, temperature control at $37^{\circ} \mathrm{C}$, and the sensors kept hydrated and in darkness. The average drift across the sensors after 100 days was $1.93 \pm 0.65 \mathrm{mmHg}$.

for up to $120 \mathrm{~min}$ (30 min before drug administration to establish a baseline and 90 min after drug administration). After each drug, a rest period of at least 2 days was allowed before administration of the next drug. For analysis, the average of a 10 -min period for each variable was taken from the baseline period and from a steady-state period after drug administration. Data from the same 10-min periods were used to plot beat-by-beat data for each drug. A second cardiac ultrasonography was obtained from six animals $4 \mathrm{wk}$ postsurgery and a minimum of 2 days following any administration of short-term drugs. This was compared with the initial ultrasound to determine whether the surgery or placement of the sensor had an effect on LV function.

Group $C$. Various doses of three different compounds were administrated starting $3.4 \pm 0.7 \mathrm{wk}$ after LV catheter implantation surgery. Verapamil $(3,10$, or $30 \mathrm{mg} / \mathrm{kg}$ ) was administered by oral gavage or the $\beta_{1}$-adrenergic agonist dobutamine $(3,10,30$, or $100 \mu \mathrm{g} / \mathrm{kg})$ or the calcium sensitizer levosimendan $(10,30$, or $100 \mu \mathrm{g} / \mathrm{kg})$ were injected as an iv bolus into the previously implanted femoral venous catheter (21). With dobutamine and levosimendan, arterial pressure was also measured via a femoral arterial catheter. Continuous recordings were made for $1 \mathrm{~min}$ before and $30 \mathrm{~min}$ after dobutamine and levosimendan administration, and data were recorded for 2 min every 10 min for 2 $\mathrm{h}$ before and for $24 \mathrm{~h}$ after verapamil.

\section{Statistical Analysis}

Statistical analysis was performed in GraphPad Prism (v6.01; GraphPad Software, CA). Comparisons between data for circadian variation, telemeter vs. acute catheter measurement, and pre- and postsurgery ultrasonography results were made by a paired $t$-test. A two-way ANOVA was performed on drug-induced changes in LVP baselines and peak change. Significance was established at $P<0.05$, and all data were reported as means $\pm \mathrm{SE}$.

\section{RESULTS}

\section{Modeled Error in Determining $d P / d t$}

Results from the Bessel filter MATLAB model show that for signals with a $\mathrm{dP} / \mathrm{d} t$ above $8,000 \mathrm{mmHg} / \mathrm{s}$, the error due to the sensor's frequency response for fluid-filled catheters may significantly dampen the signal being measured (Fig. 1B). For a rate of pressure change of $10,000 \mathrm{mmHg} / \mathrm{s}$, the predicted frequency response error from the Data Sciences telemeter model $\mathrm{C} 40$ is $>1,370 \mathrm{mmHg} / \mathrm{s}$, rising to $>12,300 \mathrm{mmHg} / \mathrm{s}$ for a signal of $23,000 \mathrm{mmHg} / \mathrm{s}$. The predicted error of the Data Sciences telemeter model $\mathrm{C} 10$ is $>170 \mathrm{mmHg} / \mathrm{s}$ for a signal with a rate of change of $10,000 \mathrm{mmHg} / \mathrm{s}$, rising to an error of $>8,600 \mathrm{mmHg} / \mathrm{s}$ for a signal of $23,000 \mathrm{mmHg} / \mathrm{s}$. Comparatively, the solid-state telemeters have a sufficiently high-fre-
A

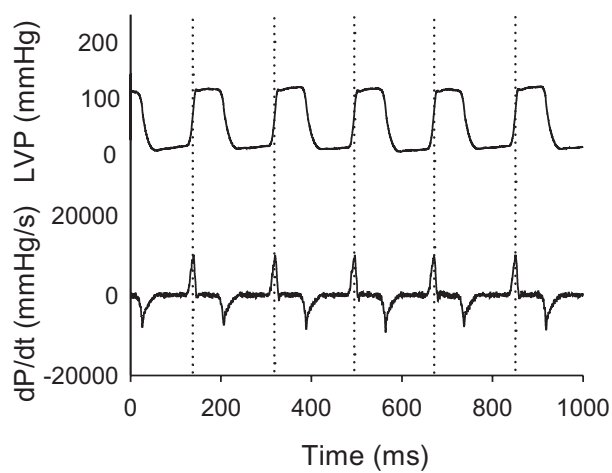

C

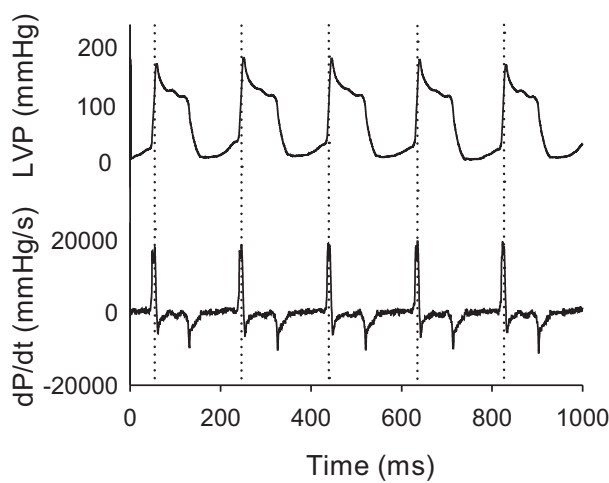

B

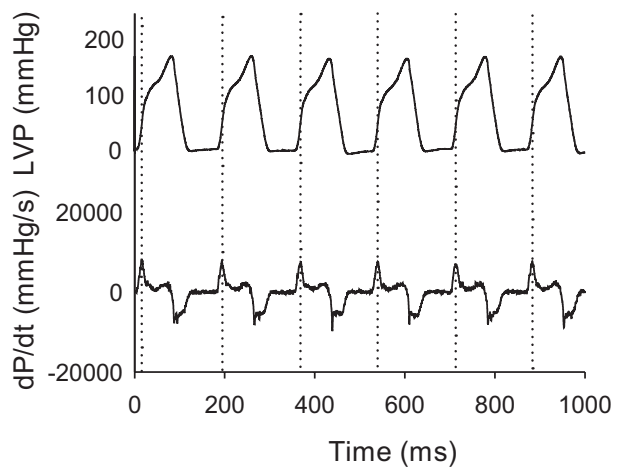

D

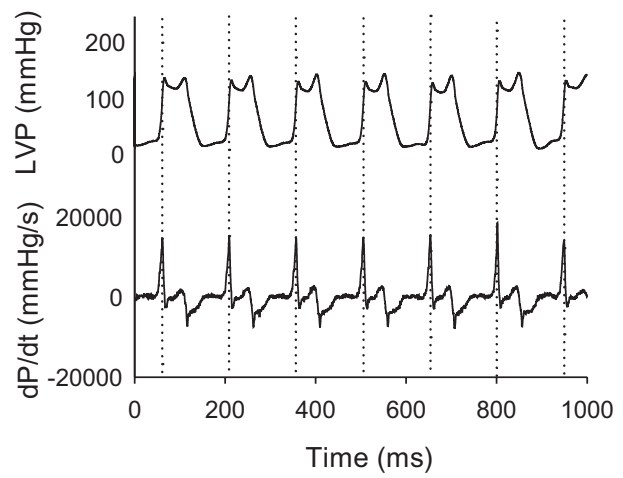

Fig. 4. Four patterns of LVP waveforms (upper trace) observed during the study and their corresponding LV $\mathrm{dP} / \mathrm{d} t$ (lower trace). Dotted lines indicate where the maximum $\mathrm{dP} / \mathrm{d} t$ occurred on the LVP waveform. A: the ideal, expected LVP waveform most commonly observed during the study with $\mathrm{dP} / \mathrm{d} t$ max occurring in the middle of the LVP upstroke. Waveforms in $B, C$, and $D$ contain abnormal spikes that are assumed to be from the heart muscle contracting against the pressure-sensing element. At least one of these waveform variations was occasionally observed in each animal. Data during these periods were excluded from further analysis if the abnormal waveform influenced the $\mathrm{dP} / \mathrm{d} t \max . B$ : an LVP waveform with a spike occurring on the LVP down-stroke. This does not influence $\mathrm{dP} / \mathrm{d} t$ max, and contractility data from these waveforms were considered valid. In $(C)$ and $(D)$ $\mathrm{dP} / \mathrm{d} t$ max occurs during the spike, typically giving abnormally large values for $\mathrm{dP} / \mathrm{d} t$ max. Therefore, periods of data with these waveform types were excluded. In general, if there was an abnormal spike in an LVP waveform that caused a $\mathrm{dP} / \mathrm{d} t$ value greater than the physiological $\mathrm{dP} / \mathrm{d} t \max$ (occurring during LVP upstroke), data would be excluded. This could also be observed from the timing of the $\mathrm{dP} / \mathrm{d} t$ max with the LV waveform. 
quency response to represent a high $\mathrm{dP} / \mathrm{d} t$ with a low predicted frequency response error without dampening the signal until well above $50,000 \mathrm{mmHg} / \mathrm{s}$.

The drift rig showed that after 100 days of monitoring, the average drift across the eight sensors was $1.93 \pm 0.65 \mathrm{mmHg}$. The drift in each sensor is shown in Fig. 3.

\section{Signal Quality}

Cardiac ultrasonography results from six of the Group A rodents showed the LVP surgery or presence of the sensor in the heart did not significantly affect cardiac function. The average fractional shortening before LVP surgery was $49.2 \pm$ $4.2 \%$, and $3-4$ wk postsurgery it was $47.9 \pm 2.5$ (means \pm SE, $P>0.05)$. The average fractional area change was $67.9 \pm$ $2.5 \%$ before surgery and $66.4 \pm 2.1 \%(P>0.05)$ postsurgery. At explantation of the telemeters the hearts appeared normal with no obvious external abnormalities. Of the 35 rats that underwent LVP sensor implantation for this study, only one animal (from Group A) was euthanized due to poor health. This was 2 days postsurgery, and the cause of the problem could not be identified.

Despite viewing the LVP signal during the surgery it was observed across all groups that in some animals the signal displayed unusual waveforms. It appeared that the pressure sensor placement had a significant effect on the quality of the waveform obtained. Figure 4 demonstrates the range of the waveforms obtained. The normal LVP has a waveform that is almost square and the maximum point on $\mathrm{dP} / \mathrm{d} t$ occurs on the upstroke of the LVP waveform. We suspect that in certain orientations the sensing tip of the catheter may be lodged in a position where it can be squashed by the ventricular wall (Fig. 4). Different LVP waveforms could be observed in single animals if the catheter had not been fully secured in place and it moved over the course of the study. This was particularly evident in the first few surgeries performed in which tissue adhesive was used to secure the catheter. In some cases,
Fig. 5. Variation in cardiac contractility from a single animal from 1 day following surgery to 30 days of implantation. Values are average LVP max, EDP, heart rate, and $\mathrm{dP} / \mathrm{d} t$ max for every $2 \mathrm{~h}$ of data sampled. There is one period of signal dropout on day 27. Circadian variation in the contractility parameter $\mathrm{dP} / \mathrm{d} t$ max and heart rate is fully established 10 days following surgery. Mean values for $\mathrm{dP} / \mathrm{d} t \max , \mathrm{dP} / \mathrm{d} t$ min, heart rate, EDP, and LVP max for this animal over the course of implantation ( 28 days) were 10,516 $\mathrm{mmHg} / \mathrm{s},-8,611 \mathrm{mmHg} / \mathrm{s}, 344 \mathrm{bpm}, 6 \mathrm{mmHg}$, and $117 \mathrm{mmHg}$, respectively.
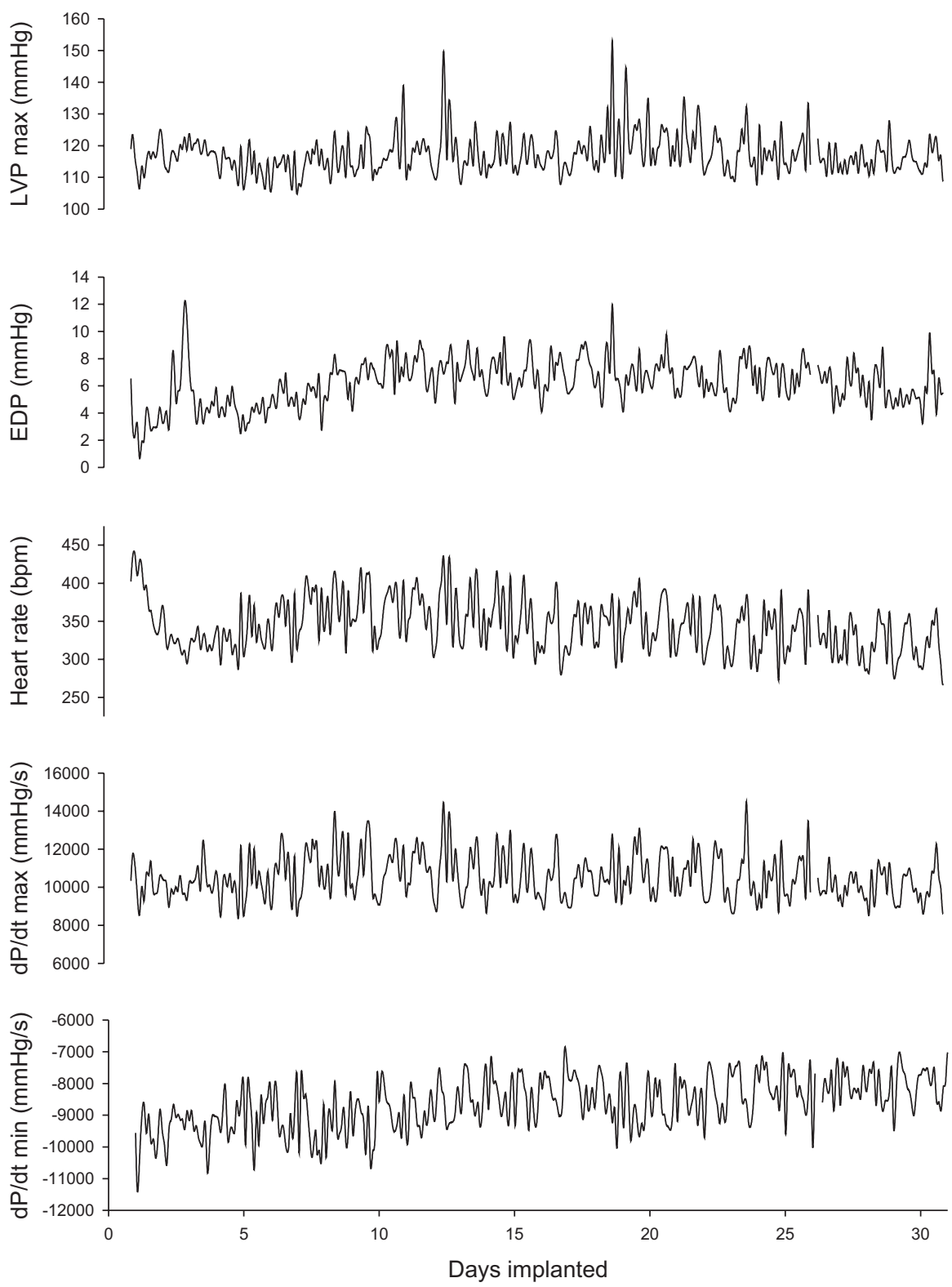
nonideal LVP waveforms could still be used for measuring the $\mathrm{dP} / \mathrm{d} t$ max, which was often unaffected by the spike in the waveform during systole. Whether or not a nonideal LVP waveform influenced $\mathrm{dP} / \mathrm{d} t$ max depended on the timing of $\mathrm{dP} / \mathrm{d} t$ max relative to the LVP shape.

At postmortem of the rats in Group B, the heart tissue was carefully dissected away to allow visualization of the pressure sensor tip. Of the 12 rats implanted in this group, 2 had the tips completely buried in the LV wall and 2 were held against the wall by tissue. The LVP waveforms from these rats were found to have the most frequent unusual shapes of Group B, including spikes as shown in Fig. 4, and also periods when the entire waveform was offset by up to $20 \mathrm{mmHg}$. Data from these four rats were excluded from further analysis. Two further animals had small bumps of tissue visible on the LV wall suggesting that the tip of the catheter may have been hitting the LV wall. From the included eight rats from Group B, no difference was found between the telemeter and acute catheter measurements of EDP $(7.8 \pm 1.4$ vs. $8.2 \pm 0.9 \mathrm{mmHg}, P=0.74), \mathrm{LVP} \max$ $(104.0 \pm 3.1$ vs. $101.5 \pm 2.2 \mathrm{mmHg}, P=0.29)$, and minimum LVP $(0.0 \pm 1.8$ vs. $0.2 \pm 0.7 \mathrm{mmHg}, P=0.86)$. In Groups $A$ and $C$, drug response data were included for animals that displayed none of the unusual waveforms as observed in Fig. 4 during the drug-response data recording period. Out of the 14 animals in Group A, 6 provided sufficiently stable drug response waveforms, resulting in 4 animals per drug. All of the 9 animals in Group $C$ contributed to the drug-response data, with between 5 and 7 animals per drug.

\section{Chronic Data}

For Group B animals, 7 out of a total of 12 LVP surgeries were considered successful on the basis of postmortem position of the pressure sensor tip and providing stable LVP signals throughout the majority of the implantation periods (28 to 40 days). LVP $\max , \mathrm{EDP}, \mathrm{HR}$, and $\mathrm{dP} / \mathrm{d} t$ max were monitored in each animal. From the seven successful preparations, an average (means \pm SE) LVP max of $118 \pm 2 \mathrm{mmHg}$, EDP of $8.2 \pm 1.4 \mathrm{mmHg}$, HR of $303 \pm 4 \mathrm{bpm}, \mathrm{dP} / \mathrm{d} t$ max of $9,444 \pm 363 \mathrm{mmHg} / \mathrm{s}$, and $\mathrm{dP} / \mathrm{d} t \mathrm{~min}$ of $-7,793 \pm 182 \mathrm{mmHg} / \mathrm{s}$ was measured in the daytime data in this group.

Figure 5 shows the variation in these parameters over 28 days in one animal. In each animal there was evidence of a circadian variation in $\mathrm{dP} / \mathrm{d} t$ max, HR, and EDP, emerging between 3 and 7 days after surgery $(P<0.05)$. The circadian variation observed across the seven animals over $24 \mathrm{~h}$ is shown in Fig. 6. There was a visible peak in the circadian data at 9-10 A.M., which is the time the laboratory technician cleaned the cages and weighed the animals each day. The 9 and 10 A.M. data points were therefore excluded from the light-to-dark differences. The average difference during the dark period (from the light period) was $+918 \pm$ $84 \mathrm{mmHg} / \mathrm{s}$ for $\mathrm{LV} \mathrm{dP} / \mathrm{d} t \max ,-675 \pm 85 \mathrm{mmHg} / \mathrm{s}$ for $\mathrm{LV} \mathrm{dP} / \mathrm{d} t$ min, $+38 \pm 3 \mathrm{bpm}$ for HR, and $1.5 \pm 0.3 \mathrm{mmHg}$ for EDP.

Group $C$ contained a total of nine animals implanted for a total period of 24 to 85 days (mean $41 \pm 8$ days).

\section{Drug-Induced Changes in LVP}

For Group A, 8 of the 11 surgeries were considered successful, giving good LVP signals throughout the majority of the implantation periods ( 28 to 44 days). One of the three animals with unsuccessful surgery had a consistently bad signal, attrib-
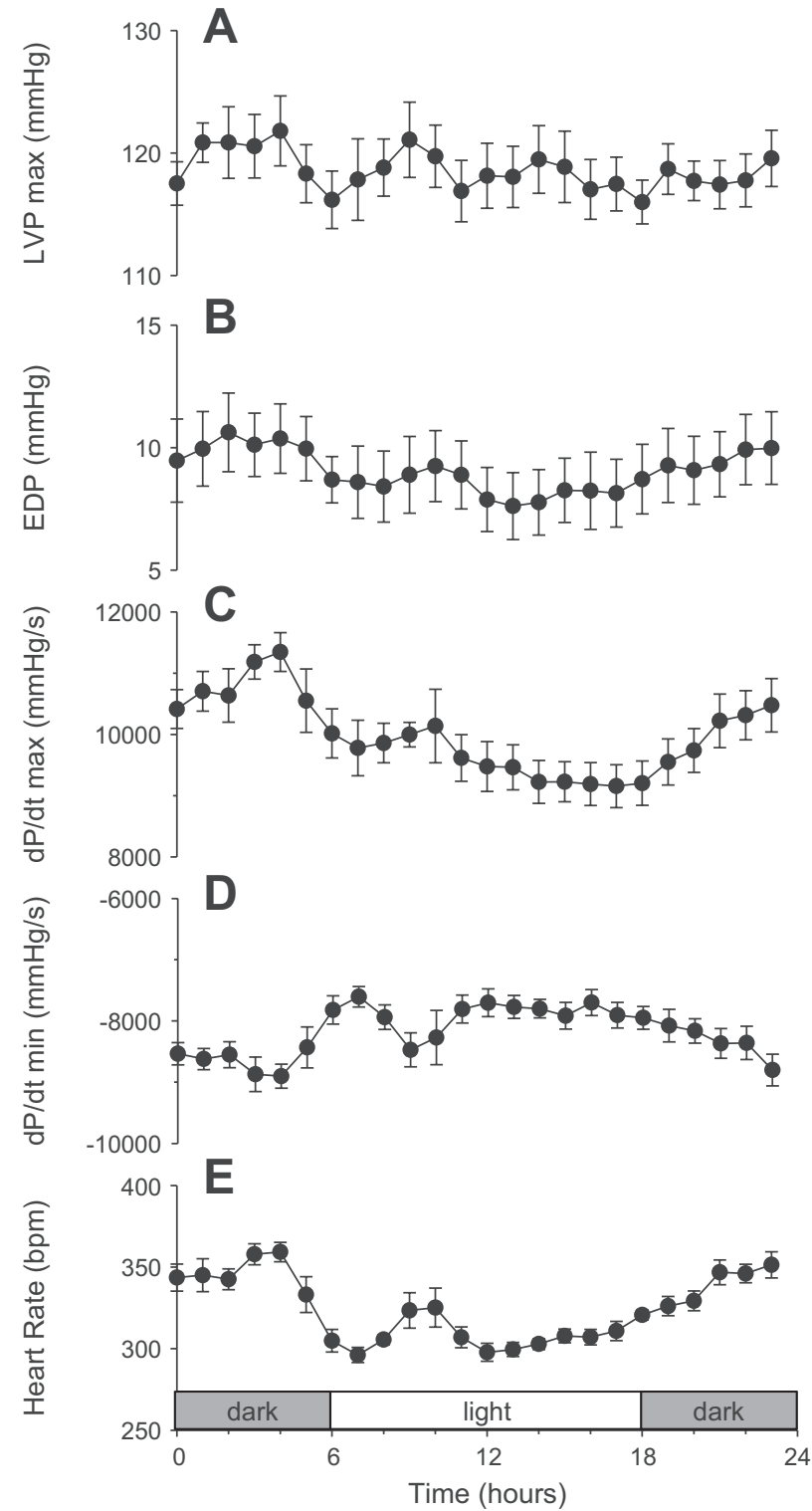

Fig. 6. Circadian variation in LVP $\max (A), \operatorname{EDP}(B), \mathrm{dP} / \mathrm{d} t \max (\mathrm{mmHg} / \mathrm{s})(C)$, $\mathrm{dP} / \mathrm{d} t \min (D)$, and heart rate $(E)$ across $24 \mathrm{~h}$. Each point is means \pm SE per hour across 5 days in 7 animals. The average difference from light (white bar) to dark (dark bar) phases in LV $\mathrm{dP} / \mathrm{d} t \max$ was $+918 \pm 84 \mathrm{mmHg} / \mathrm{s}$, in $\mathrm{LV}$ $\mathrm{dP} / \mathrm{d} t \mathrm{~min}-675 \pm 85 \mathrm{mmHg} / \mathrm{s}$, and in heart rate $+38 \pm 3 \mathrm{bpm}$. There was no circadian influence on LVP max and EDP.

uted to poor placement of the catheter in the heart, and was euthanized 12 days after surgery. The catheters in the remaining two animals were pulled out of the heart early after 9 and 13 days of implantation. These animals were both early in the model development with only tissue adhesive used to secure the catheter.

In subsequent analysis the data were included only if the waveform shape was deemed to be acceptable. In Group A, the maximum effect of the drugs was observed 30-60 min after drug administration. The typical response from a single animal to different compounds is shown in Fig. 7, with the average effect on the eight animals shown in Fig. 8. Verapamil increased HR from $285 \pm 8$ to $340 \pm 4 \mathrm{bpm}(P<0.05)$, with a decrease in $\mathrm{dP} / \mathrm{d} t$ max from $10,107 \pm 550$ to $6,102 \pm 899$ 
A

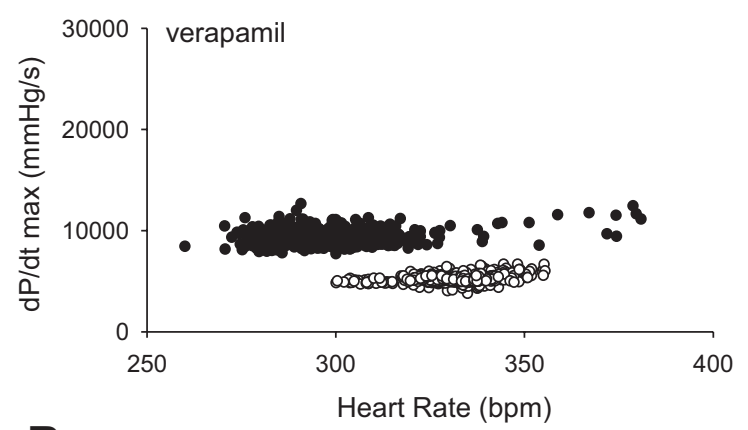

B

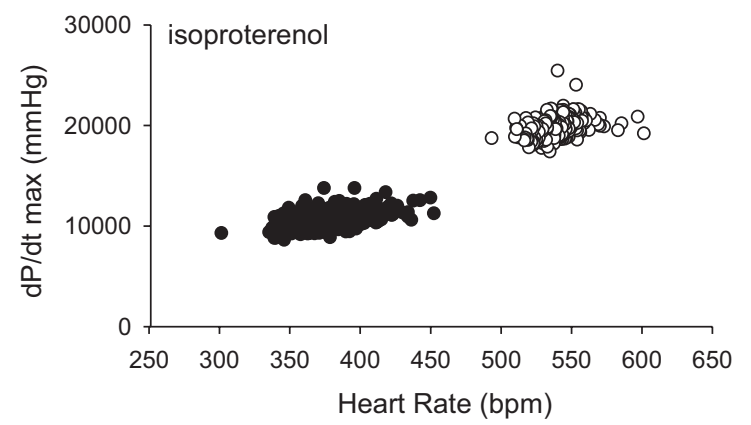

Fig. 7. Bowditch plots of an individual animal's response to subcutaneous injection of $10 \mathrm{mg} / \mathrm{kg}$ verapamil $(A)$ and $10 \mu \mathrm{g} / \mathrm{kg}$ isoproterenol $(B)$. HR and $\mathrm{dP} / \mathrm{d} t$ were measured from $10 \mathrm{~min}$ of control data prior to injection (closed circles) and $10 \mathrm{~min}$ of postinjection drug data (open circles) when the maximum effect was observed.

$\mathrm{mmHg} / \mathrm{s}(P<0.05)$. Isoproterenol increased both HR $(320 \pm$ 16 to $498 \pm 23 \mathrm{bpm})$ and $\mathrm{dP} / \mathrm{d} t \max (9,380 \pm 923$ to $16,110 \pm$ $2,283 \mathrm{mmHg} / \mathrm{s})(P<0.05)$.

In Group $C$, po verapamil and iv dobutamine or levosimendan elicited dose- and time-dependent hemodynamic effects. Verapamil caused a significant decrease in $\mathrm{dP} / \mathrm{d} t$ max, LVP max, and an increase in HR $(P<0.05)$ with no effect on EDP. The dose-dependent effect of verapamil was significant for $\mathrm{dP} / \mathrm{d} t$ max and LVP $\max (P<0.05)$, but not HR or EDP $(P>$ $0.05)$. At the highest dose, verapamil decreased $\mathrm{dP} / \mathrm{d} t \max$ from 11,000 to $5,000 \mathrm{mmHg} / \mathrm{s}$ for $\sim 18 \mathrm{~h}$ (Fig. 9). Dobutamine had a significant effect on $\mathrm{dP} / \mathrm{d} t$ max and $\mathrm{HR}(P<0.05)$, with no overall effect on mean arterial pressure (MAP) or EDP. At the highest dose, dobutamine increased HR and more than doubled $\mathrm{dP} / \mathrm{d} t$ max with the effects dissipating within $5 \mathrm{~min}$. The time-dependence of dobutamine at $100 \mu \mathrm{g} / \mathrm{kg}$ is evident in Fig. 10. MAP was transiently increased at the two lowest doses but transiently decreased at 30 and $100 \mu \mathrm{g} / \mathrm{kg}$. As a result, the dose-dependence of dobutamine was significant $(P<0.05)$ for MAP and for $\mathrm{dP} / \mathrm{d} t$ max and HR, but not for EDP. Levosimendan also nearly doubled $\mathrm{dP} / \mathrm{d} t$ max, increased $\mathrm{HR}$, and decreased MAP $(P<0.05)$, with no effect on EDP (Fig. 11). The $\mathrm{dP} / \mathrm{d} t$ max and $\mathrm{HR}$ responses lasted for $\sim 20 \mathrm{~min}$ and had dose-dependent significance $(P<0.05)$, whereas the MAP effect was transient and not influenced by dose $(P>0.05)$.

\section{DISCUSSION}

In the present study we used a telemeter that incorporated a solid-state pressure sensor at the tip to record LVP in rats living in their home cage. We established a reliable surgical approach for placement of the sensor and validated that the technology was capable of correctly measuring high values of $\mathrm{dP} / \mathrm{d} t$ (high-frequency response). We were able to record stable LVP signals for the duration of the study (a maximum of 85 days) and observed strong circadian variation in $\mathrm{dP} / \mathrm{d} t$. This study also demonstrated the ability to measure pronounced changes in the contractility index, $\mathrm{dP} / \mathrm{d} t \max$ (from $-6,000$ to $+13,000$ $\mathrm{mmHg} / \mathrm{s}$ ), in response to a variety of compounds. The validation of the surgery and technology confirms use of the highfidelity pressure-sensing telemetry for chronically and accurately monitoring cardiac function in conscious, freely moving rats.

The chronic measurement of LVP and associated $\mathrm{dP} / \mathrm{d} t$ in freely moving rodents has considerable potential to assist in basic physiological/pharmacological research. Monitoring through a disease process such as before and after myocardial infarction or during treatment for heart failure could be enabled if a reliable measurement of LVP can be made. Chronic recording allows not only for a timeline of response to be established but also for measurements to be made inside physiological operating ranges, which are often depressed in acute, anesthetized animal experiments (8). From the accurate recording of LVP, measurements of the contractility index, $\mathrm{dP} / \mathrm{d} t \max$, can be made. Although somewhat susceptible to preload and HR de-

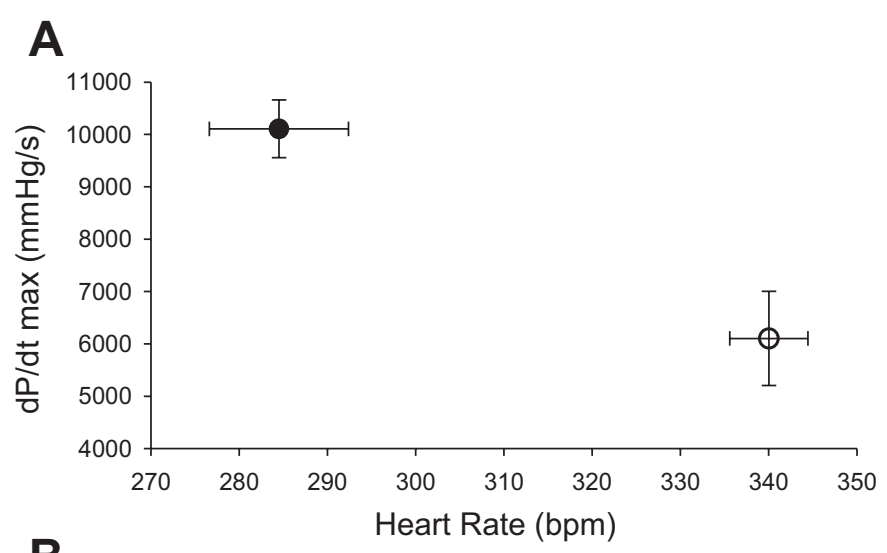

B

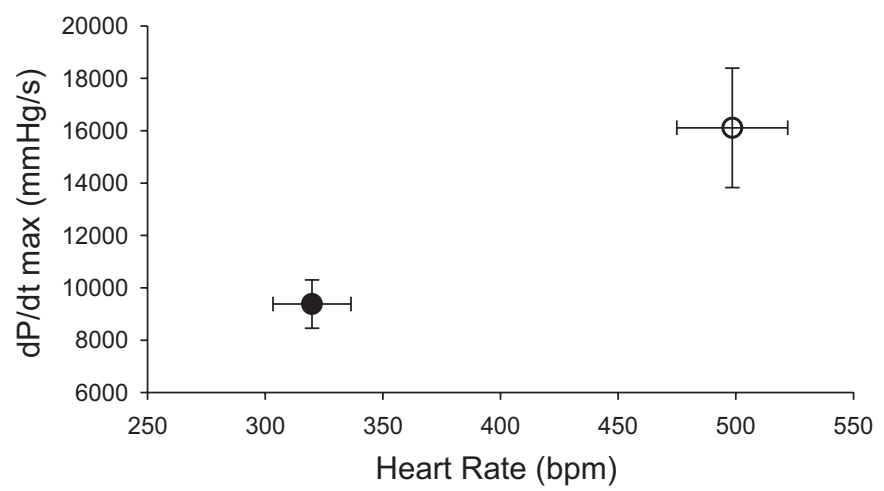

Fig. 8. Response to subcutaneous injection of verapamil $(10 \mathrm{mg} / \mathrm{kg}, n=4)(A)$ and isoproterenol $(10 \mu \mathrm{g} / \mathrm{kg}, n=4)(B)$ as measured by the pressure sensor implanted in the left ventricle. Data are means across $n$ animals from $10 \mathrm{~min}$ of data prior to injection (closed circle) and postinjection when the maximum effect was observed (open circle). Verapamil increased HR by $55 \pm 9 \mathrm{bpm}$ (means $\pm \mathrm{SE}$ ) and isoproterenol increased it by $178 \pm 19 \mathrm{bpm}$. Verapamil decreased $\mathrm{dP} / \mathrm{d} t$ max by $4,005 \pm 380 \mathrm{mmHg} / \mathrm{s}$ (means $\pm \mathrm{SE}$ ) and isoproterenol increased it by $6,729 \pm 1,390 \mathrm{mmHg} / \mathrm{s}$. 

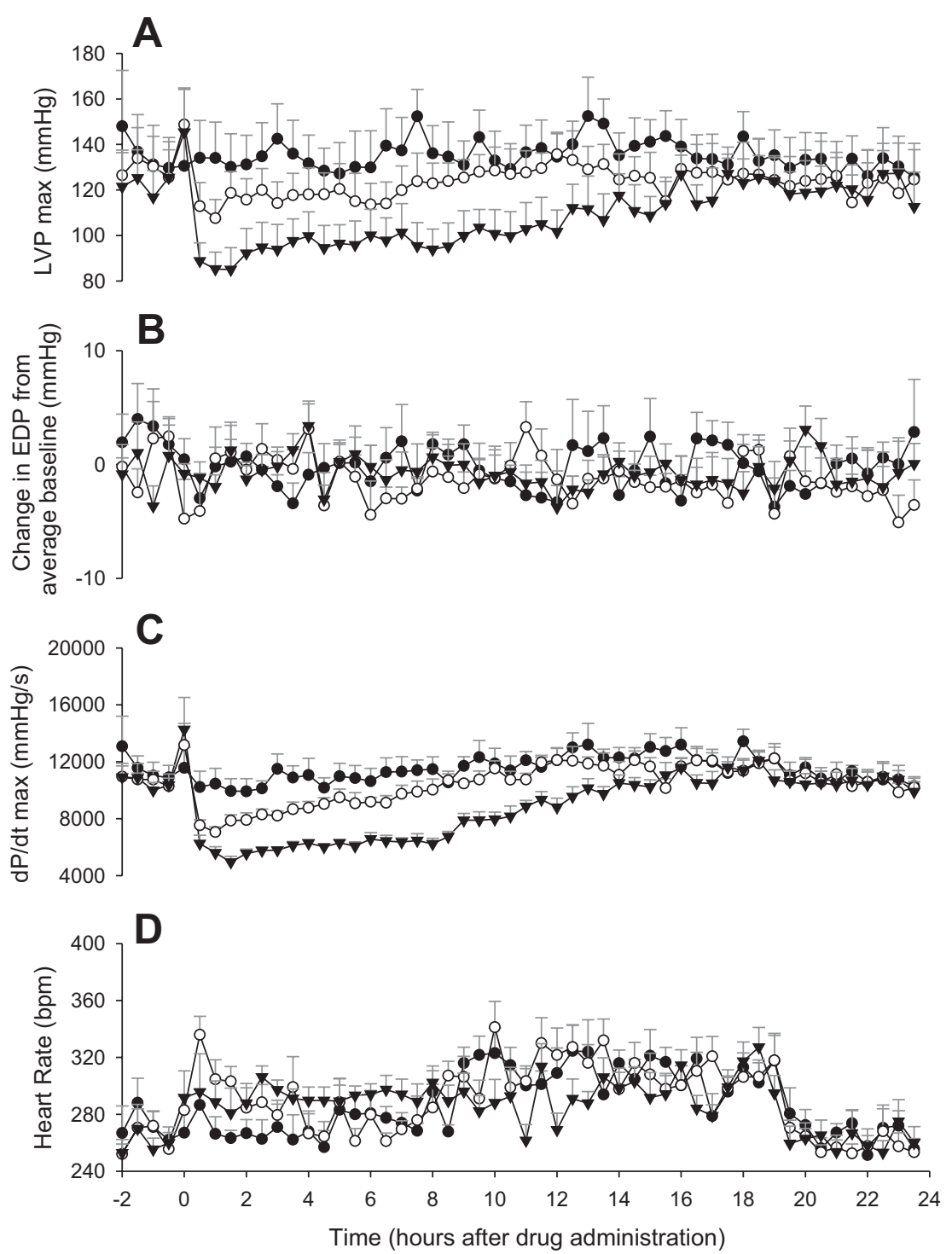

Fig. 9. Verapamil time course and dose response for $3(\bullet)$, $10(\bigcirc)$, and $30(\mathbf{v}) \mathrm{mg} / \mathrm{kg}$ po $(n=7)$. Two minutes of data were recorded every $10 \mathrm{~min}$ from $2 \mathrm{~h}$ prior to administration to $24 \mathrm{~h}$ postadministration. Data shown are the average of the three 2-min periods recorded each half hour. Verapamil at $30 \mathrm{mg} / \mathrm{kg}$ decreased $\mathrm{dP} / \mathrm{d} t$ max from 11,000 $\mathrm{mmHg} / \mathrm{s}$ to $5,000 \mathrm{mmHg} / \mathrm{s}$ and decreased LVP $\max$ from $120 \mathrm{mmHg}$ to $85 \mathrm{mmHg}$ with the effect lasting $\sim 18 \mathrm{~h}$. A transient increase in HR was observed with no effect on EDP. pendence, $\mathrm{dP} / \mathrm{d} t$ max is a proven measure of cardiac function due to its high sensitivity to contractility, and afterload independence $(6,9,12,19,22,26)$. In addition to establishing a surgical approach we have collated a library of responses to common compounds known to affect cardiac function. These data are important in being able to compare novel compounds and in assessing the progression of a disease state.

Although there have been previous reports of LVP measurement $(1,3,4,15,16,18,20,23,24)$, few include data from conscious, unrestrained rodents, and the $\mathrm{dP} / \mathrm{d} t$ values reported (up to $13,000 \mathrm{mmHg} / \mathrm{s}$ ) could be significantly underestimated possibly by up to $60 \%$ due to the fluid-filled catheter approach. Sato et al. monitored LVP in the conscious rat for up to $2 \mathrm{wk}$ using DSI C40 pressure transmitters with a reported circadian variation from light to dark in $\mathrm{dP} / \mathrm{d} t$ max of $\sim 500 \mathrm{mmHg} / \mathrm{s}$ and in HR variation of $+54 \mathrm{bpm}(23)$. Our results showed a mean value of $\mathrm{LV} \mathrm{dP} / \mathrm{d} t$ max of $9,443 \mathrm{mmHg} / \mathrm{s}$ and $10,361 \mathrm{mmHg} / \mathrm{s}$ for light and dark phases, and a difference in HR of $+38 \mathrm{bpm}$. Whereas the circadian variation in HR in our study is less than that of the Sato et al. report, the circadian variation in $\mathrm{dP} / \mathrm{d} t$ max of $918 \mathrm{mmHg} / \mathrm{s}$ is larger and the $\mathrm{dP} / \mathrm{d} t$ max is consistently larger in both the light and dark periods. From our analysis of frequency-response associated error in the different pressure transmitters we propose that the pressure telemeter used by Sato et al. may potentially have an error of $>1,370 \mathrm{mmHg} / \mathrm{s}$ at a $\mathrm{dP} / \mathrm{d} t$ max of $10,000 \mathrm{mmHg} / \mathrm{s}(>14 \%)$. It is expected that this would have significantly dampened the circadian variation recorded during the higher-intensity dark phase. In comparison, the high-fidelity sensor used in our study has a frequency response associated error of $80 \mathrm{mmHg} / \mathrm{s}(<1 \%)$ at $\mathrm{dP} / \mathrm{d} t$ levels of $10,000 \mathrm{mmHg} / \mathrm{s}$. The high-frequency response of the solidstate telemeter allows for a more accurate measure of the circadian variation in $\mathrm{dP} / \mathrm{d} t$ max to be obtained. Our results show a circadian variation in the contractility parameter, LV $\mathrm{dP} / \mathrm{d} t$ max, much greater than that which has been previously reported.

A recent study by Adeyemi et al. examined the use of the QA interval (interval between the $\mathrm{Q}$ wave derived from the ECG and the onset of the arterial pressure waveform) as a measure of cardiac contractility by comparing how the QA interval changed in response to drug administration against how LV dP/d $t$ max changed (1). Fluid-filled catheter-based 
Fig. 10. Dobutamine time course and dose response for 3 $(\bullet), 10(\bigcirc), 30(\nabla)(n=6)$, and $100(\triangle)(n=5) \mu \mathrm{g} / \mathrm{kg}$ iv. Continuous data were recorded from $1 \mathrm{~min}$ prior to administration to 30 min postadministration. Data shown are the average for every $10 \mathrm{~s}$. Dobutamine at $100 \mu \mathrm{g} / \mathrm{kg}$ increased heart rate from $275 \mathrm{bpm}$ to a maximum of $438 \mathrm{bpm}$, and increased $\mathrm{dP} / \mathrm{d} t$ max from $10,000 \mathrm{mmHg} / \mathrm{s}$ to 23,000 $\mathrm{mmHg} / \mathrm{s}$ with the effect lasting less than $5 \mathrm{~min}$. Mean arterial pressure was transiently increased with 3 and 10 $\mu \mathrm{g} / \mathrm{kg}$, but decreased with the higher doses of 30 and 100 $\mu \mathrm{g} / \mathrm{kg}$. No effect was observed on EDP.
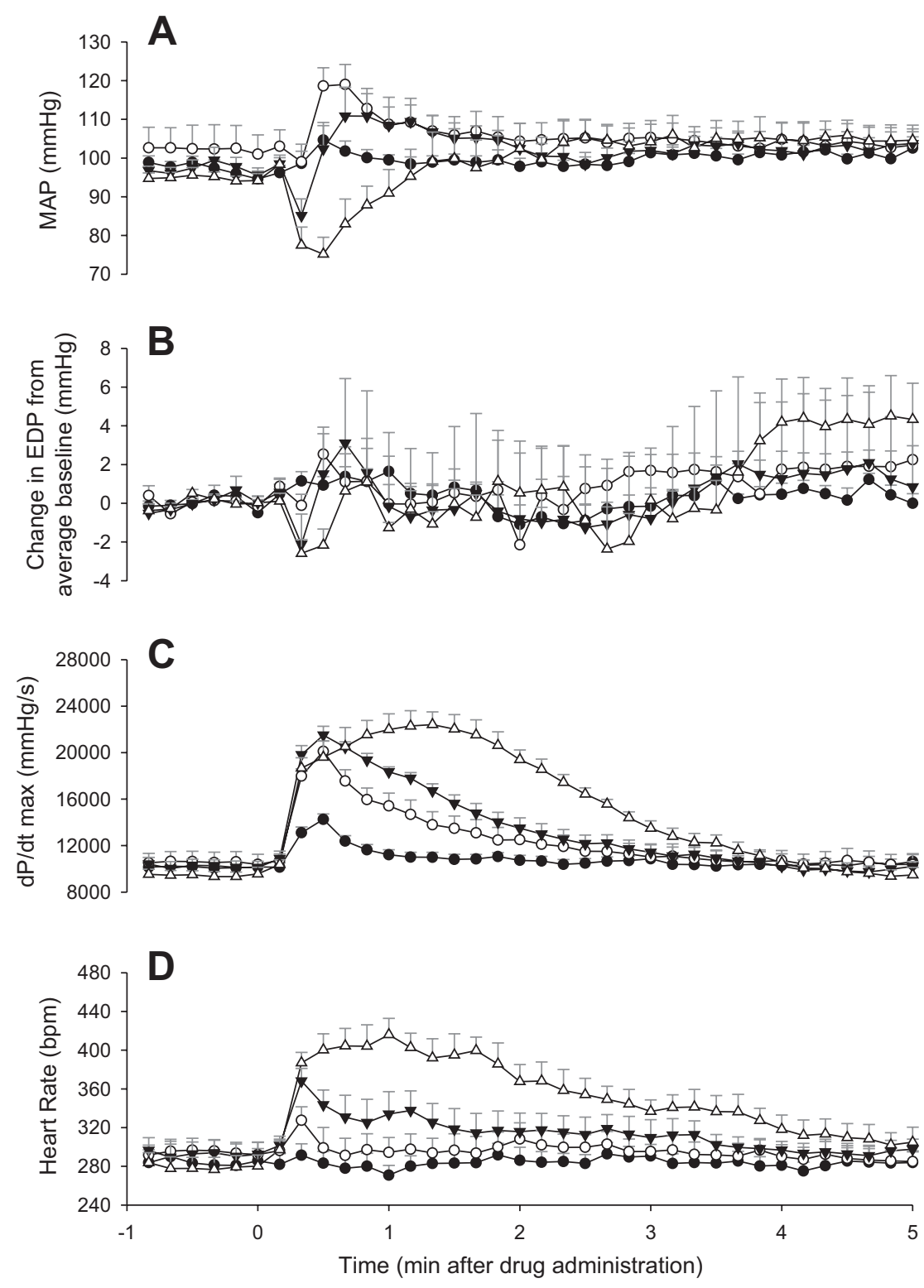

pressure telemetry was used to measure LVP (DSI C10) in a separate group of animals to those implanted with aortic pressure and ECG telemetry. Due to the nature of the increasing frequency response error with increasing contractility, baseline measures of $\mathrm{dP} / \mathrm{d} t$ max in that study are likely to be accurate, but when drugs were used to increase $\mathrm{dP} / \mathrm{d} t \max$ up to $12,000 \mathrm{mmHg} / \mathrm{s}$ there is an estimated corresponding error of $800 \mathrm{mmHg} / \mathrm{s}$ for the $\mathrm{C} 10$ transmitter. As a result, there may have been some dampening of the drug's effect on $\mathrm{dP} / \mathrm{d} t \max$ that could introduce error in the correlation between changes in $\mathrm{dP} / \mathrm{d} t$ being reflected in changes in the QA interval. This would have major consequences when using such results to provide an estimate of $\mathrm{dP} / \mathrm{d} t$.

The position and securing of the sensor in the LV was found to be a vital component of ensuring valid chronic LVP data were being obtained. The assumption that the waveform shape relies on correct orientation of the sensor was due to our ability to replicate the unusual waveforms during surgery by inserting the catheter too far, or not fully through the apex of the heart.
The location of the pressure-sensing element, on the side of the catheter, supports the notion that the heart muscle may be contracting against the element, causing constructive interference to the LV fluid pressure waveform with muscular force. This theory is also supported by the observation that unusual waveforms were common after isoproterenol, dobutamine, and levosimendan administration and during dark hours-periods when contractility was increased. We found that viewing the signal during surgery helped to ensure the catheter tip was correctly placed in the LV. However, inserting the catheter through the apex only far enough to obtain an acceptable signal during surgery was likely to result in signals with more frequent artifacts than if the catheter tip was placed further into the LV. This is believed to be due to the narrowness of the LV chamber near the apex compared with toward the base. Securing the catheter using the purse-string and thread (or tubing cuff) technique was found to decrease the incidence of nonideal waveforms and therefore assumed to be the most successful method of securing the sensor. Interestingly, the opti- 

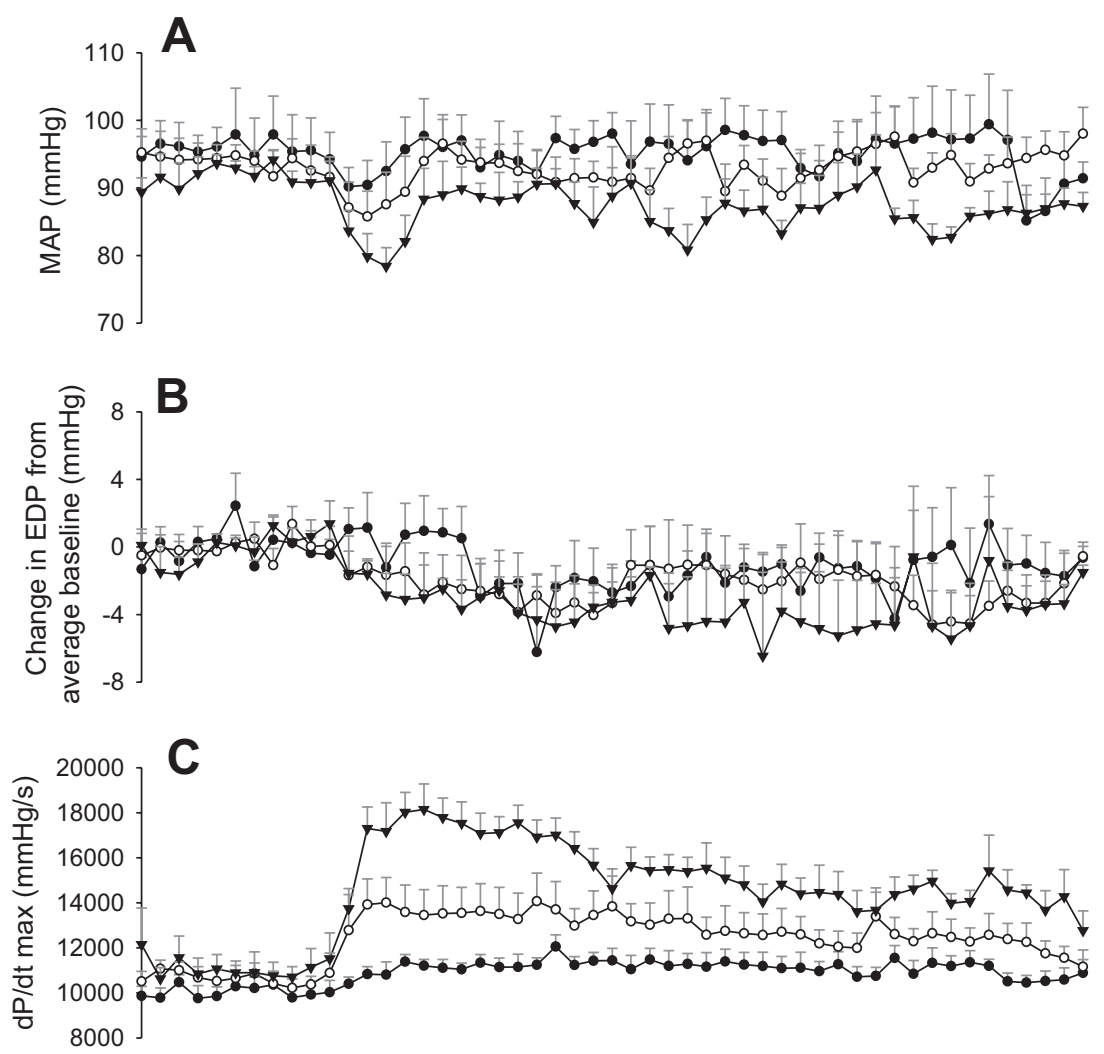

Fig. 11. Levosimendan time course and dose response for $10(\bullet), 30(0)$, and $100(\mathbf{v}) \mu \mathrm{g} / \mathrm{kg}$ iv $(n=5)$. Continuous data were recorded from $2 \mathrm{~min}$ prior to administration to 20 min postadministration. The 10 -s average for every $30 \mathrm{~s}$ is displayed. The highest dose of $100 \mu \mathrm{g} / \mathrm{kg}$ increased $\mathrm{dP} / \mathrm{d} t$ max from $11,000 \mathrm{mmHg} / \mathrm{s}$ to more than $18,000 \mathrm{mmHg} / \mathrm{s}$, increased HR from $300 \mathrm{bpm}$ to $400 \mathrm{bpm}$, and transiently decreased MAP. No effect was observed on EDP.

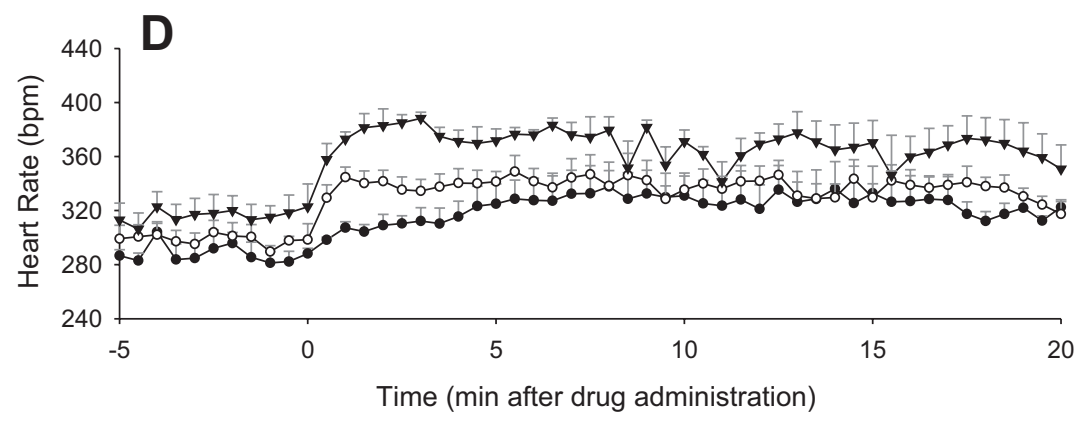

mal distance of insertion into the LV (10 mm in Group A and $9 \mathrm{~mm}$ in Group $C$ ) was independently found to be similar between the two groups of rats despite a significant variation in animal size and weight (300-715 g). The results of ultrasounds performed on each rat in Group A prior to and after recovery from surgery confirm that the chronic placement of the catheter had no significant influence on cardiac function. Once the surgical method had been established in Group A, 7 of the 12 rats from Group $B$ were able to be included in analysis of the chronic data. As with any new surgical technique, the surgeons grew more comfortable with the placement of the LVP catheter throughout the study, and we expect our further improvement in our success rates in future studies. Anecdotally, the process of opening the LV postmortem to view the catheter tip placement was very useful for refining placement of the catheter for future surgeries.

It was observed that in a few animals during the recordings following administration of isoproterenol, dobutamine, and levosimendan the incidence of abnormal waveform (spikes) occurring on the LVP waveform increased. This was particu- larly evident in animals that had shown evidence of intermittent spikes on the signal previously but could also occur in animals in which the signal had been stable until that point. The spikes on the signal generally resolved as the heart rate and contractility effects of the drug subsided and were not evident when $\mathrm{dP} / \mathrm{d} t$ was decreased with verapamil. Therefore, we assume they are caused by the large, positive, inotropic effect of these drugs, which increase contractility, causing the ventricular wall to squeeze down on the catheter tip. Although not reported here, the unusual waveforms would have affected variables such as LV systolic pressure, highlighting the importance of recording and observing the raw waveform shape and any calculated variables.

In conclusion, this study has demonstrated the ability of new solid-state telemetry to chronically and accurately measure $\mathrm{LVP}$ and $\mathrm{LV} \mathrm{dP} / \mathrm{d} t$ in conscious, freely moving rats. The circadian variation and drug-induced changes have been measured to a resolution finer than the frequency response-associated error in fluid-filled catheter-based pressure-sensor telemeters. The surgical approach did not influence contractility and 
was refined to ensure interference-free LVP waveforms could be obtained for extended periods. We propose that this technique and associated data provide the basis for examining cardiac function in a variety of research paradigms, including drug evaluation and basic research with disease models.

\section{GRANTS}

Support for this study was provided by grants from the Foundation of Science Research \& Technology, Health Research Council of New Zealand, and Auckland Medical Research Foundation. C. Barrett is the recipient of the Hercus Fellowship from the Health Research Council of New Zealand.

\section{DISCLOSURES}

S. Malpas is a Director in the company Millar Inc. S.-J. Guild, D. Budgett, and D. McCormick are employed by Millar Inc. Millar Inc. supplied the telemeters and SmartPads used in this study.

\section{AUTHOR CONTRIBUTIONS}

Author contributions: S.C.M., D.M.B., D.J.M., D.F.R., and S.-J.G. conception and design of research; E.S., C.J.B., F.F., M.B., D.F.R., and S.-J.G. performed experiments; E.S., G.W., F.F., M.B., D.F.R., and S.-J.G. analyzed data; E.S., D.F.R., and S.-J.G. interpreted results of experiments; E.S. prepared figures; E.S. drafted manuscript; E.S., S.C.M., D.M.B., C.J.B., D.J.M., D.F.R., and S.-J.G. edited and revised manuscript; S.C.M., D.M.B., C.J.B., D.J.M., D.F.R., and S.-J.G. approved final version of manuscript.

\section{REFERENCES}

1. Adeyemi O, Roberts S, Harris J, West H, Shome S, Dewhurst M. QA interval as an indirect measure of cardiac contractility in the conscious telemeterised rat: model optimisation and evaluation. J Pharmacol Toxicol Methods 60: 159-166, 2009.

2. Budgett DM, Hu AP, Pallaw WT, Donnelly MG, Broad JW, Barrett CJ, Guild SJ, Malpas SC. Novel technology for the provision of power to implantable physiological devices. J Appl Physiol 102: 1758-1663, 2007.

3. Capasso JM, Palackal T, Olivetti G, Anversa P. Left ventricular failure induced by long-term hypertension in rats. Circ Res 66: 1400-1412, 1990.

4. Coimbra R, Sanchez LS, Potenza JM, Rossoni LV, Amaral SL, Michelini LC. Is gender crucial for cardiovascular adjustments induced by exercise training in female spontaneously hypertensive rats? Hypertension 52: 514-521, 2008.

5. Data Sciences International. DSI Pressure Sensing Technologies in Small Animal Chronic Monitoring Applications, New Brigton, MN, 2010.

6. Gleason WL, Braunwald E. Studies on the first derivative of the ventricular pressure pulse in man. J Clin Invest 41: 80-91, 1962.

7. Guild SJ, Barrett CJ, McBryde FD, Van Vilet BN, Malpas SC. Sampling of cardiovascular data; how often and how much? Am J Physiol Regul Integr Comp Physiol 295: R510-R515, 2008.

8. Kass DA, Hare JM, Georgakopoulos D. Murine cardiac function: a cautionary tail. Circ Res 82: 519-522, 1998.

9. Kass DA, Maughan WL, Guo ZM, Kono A, Sunagawa K, Sagawa K. Comparative influence of load versus inotropic states on indexes of ventricular contractility: experimental and theoretical analysis based on pressure-volume relationships. Circulation 76: 1422-1436, 1987. [Erratum. Circulation 77(3): 559, 1988.]
10. Kurtz TW, Griffin KA, Bidani AK, Davisson RL, Hall JE. Recommendations for blood pressure measurement in humans and experimental animals. Part 2: blood pressure measurement in experimental animals: a statement for professionals from the subcommittee of professional and public education of the American Heart Association council on high blood pressure research. Hypertension 45: 299-310, 2005.

11. Leung JM. Cardiac and Vascular Anesthesia: the requisites in anesthesiology. St. Louis, MO: Mosby, 2004.

12. Mahler F, Ross J Jr, O'Rourke RA, Covell JW. Effects of changes in preload, afterload and inotropic state on ejection and isovolumic phase measures of contractility in the conscious dog. Am J Cardiol 35: 626-634, 1975.

13. McCormick D, Budgett DM, Lim MK, Van Vliet B, Nielsen PF, Hu AP, Malpas SC. Frequency response of implantable blood pressure telemetry systems. Clin Exp Pharmacol Physiol 37: 862-869, 2010.

14. Mensor Corporation. Mensor/WIKA CPT 6100 Series Operating Instructions, San Marcos, TX, 2011.

15. Morgan EE, Faulx MD, McElfresh TA, Kung TA, Zawaneh MS, Stanley WC, Chandler MP, Hoit BD. Validation of echocardiographic methods for assessing left ventricular dysfunction in rats with myocardial infarction. Am J Physiol Heart Circ Physiol 287: H2049-H2053, 2004.

16. Nemoto S, DeFreitas G, Mann DL, Carabello BA. Effects of changes in left ventricular contractility on indexes of contractility in mice. Am J Physiol Heart Circ Physiol 283: H2504-H2510, 2002.

17. Norton K, Iacono G, Vezina M. Assessment of the pharmacological effects of inotropic drugs on left ventricular pressure and contractility: an evaluation of the QA interval as an indirect indicator of cardiac inotropism. J Pharmacol Toxicol Methods 60: 193-197, 2009.

18. Pacher P, Nagayama T, Mukhopadhyay P, Batkai S, Kass DA. Measurement of cardiac function using pressure-volume conductance catheter technique in mice and rats. Nat Protoc 3: 1422-1434, 2008.

19. Quinones MA, Gaasch WH, Alexander JK. Influence of acute changes in preload, afterload, contractile state and heart rate on ejection and isovolumic indices of myocardial contractility in man. Circulation 53: 293-302, 1976

20. Raya TE, Gay RG, Lancaster L, Aguirre M, Moffett C, Goldman S. Serial changes in left ventricular relaxation and chamber stiffness after large myocardial infarction in rats. Circulation 77: 1424-1431, 1988.

21. Rigel DF, Fu F, Beil M, Hu CW, Liang G, Jeng AY. Pharmacodynamic and pharmacokinetic characterization of the aldosterone synthase inhibitor FAD286 in two rodent models of hyperaldosteronism: comparison with the 11beta-hydroxylase inhibitor metyrapone. J Pharmacol Exp Ther 334: 232-243, 2010.

22. Sagawa K. The ventricular pressure-volume diagram revisited. Circ Res 43: 677-687, 1978.

23. Sato K, Kandori H, Sato S. Evaluation of a new method using telemetry for monitoring the left ventricular pressure in free-moving rats. J Pharmacol Toxicol Methods 31: 191-198, 1994.

24. Schenk J, Hebden A, McNeill JH. Measurement of cardiac left ventricular pressure in conscious rats using a fluid-filled catheter. J Pharmacol Toxicol Methods 27: 171-175, 1992.

25. Van Vliet BN, Chafe LL, Antic V, Schnyder-Candrian S, Montani JP. Direct and indirect methods used to study arterial blood pressure. $J$ Pharmacol Toxicol Methods 44: 361-373, 2000.

26. Wallace AG, Skinner NS Jr, Mitchell JH. Hemodynamic determinants of the maximal rate of rise of left ventricular pressure. Am J Physiol 205: 30-36, 1963. 